\title{
Association between rheumatoid arthritis and systemic mastocytosis: a case report and literature review
}

Ichraq LATAR ${ }^{1 *}$, Meriem KOUFANY ${ }^{1 *}$, Julie HABLOT ${ }^{1}$, Damien LOEUILLE ${ }^{2}$, Patrick

NETTER $^{1}$, Jean-Yves JOUZEAU ${ }^{1}$, Isabelle CHARY-VALCKENAERE ${ }^{2 \dagger}$ and David MOULIN $^{1+}$

"Ichraq LATAR and Meriem KOUFANY contributed equally to this work.

${ }^{\dagger}$ Isabelle CHARY-VALCKENAERE and David MOULIN contributed equally to this work.

Authors' affiliations: ${ }^{1}$ UMR 7365 IMoPA CNRS-Université de Lorraine, Biopôle de l'Université de Lorraine, Campus biologie-santé, 54505, Vandœuvre-lès-Nancy cedex, FRANCE. ${ }^{2}$ Department of Rheumatology, Nancy University Hospital, 54511, Vandœuvre -lès-Nancy, FRANCE.

Conflict of interest: the authors declare they have no conflicts of interest 


\section{Abstract}

Classically, mast cells (MC) are considered as important actors of the innate immune response playing a pivotal role in IgE-mediated allergic and anti-parasite responses. In the last two decades, many experimental evidences demonstrated that these hematopoietic-derived cells present in both connective and mucosal tissues are also key modulators of the adaptive immune response and could contribute to autoimmune disease notably in rheumatoid arthritis (RA). Recently, Bader-Meunier et al., reported a series of 31 patients suffering from inflammatory joint diseases associated with mastocytosis, suggesting that mastocytosis was associated with a higher prevalence in spondyloarthritis. We discuss here the possible link between chronic inflammatory arthritis and mastocytosis through the report of a clinical case describing a patient developing RA after a long history of mastocytosis. Of great interest, antihistamine treatment alone was sufficient to treat RA in this patient.

Key words: mastocytosis - rheumatoid arthritis - osteoporosis - mast cells 


\section{$\underline{\text { Case report }}$}

Our patient is a Caucasian male aged 78 years. His past medical history included a chronic obstructive pulmonary disease that led the patient to smoking cessation in 1975 (30 Packyear). In 1999, patient was admitted to rheumatology department for multiple recurrent bone fractures (vertebral compression fracture, pelvis, acetabulum, ribs, feet, left hip bone, sternum) associated with urticaria pigmentosa. Diagnosis of bone and cutaneous mastocytosis was established after bone and skin biopsies analysis. Furthermore, DEXA analysis of bone mineral density revealed major osteoporosis (T-score at -4.1 on lumbar spine and -2.6 on hip).

Since establishment of the diagnosis, the patient had received bisphosphonates (injectable pamidronate for two years, then oral alendronate) associated with vitamin D (400UI/d) and calcium $(1 \mathrm{~g} / \mathrm{d})$ supplementation. He was also prescribed a daily oral intake of selective $\mathrm{H} 1$ receptor antagonist (cetirizine $10 \mathrm{mg}$ bid). After two years of anti-osteoporotic treatment, the patient did not present any new fractures and showed an improvement of bone mineral density with stable and normal values leading to bisphophonates discontinuation in 2010. In the meantime, the patient decided to stop antihistamine treatment on his own in 2005.

In june 2012, mastocytosis flared up with severe cutaneous signs and new lumbar spine fracture. High tryptase levels $(>20 \mu \mathrm{g} / \mathrm{L})$, indicative of systemic mastocytosis, were found at this time. Patient underwent L5 vertebroplasty and antihistamine treatment was reintroduced (cetirizine $10 \mathrm{mg} / \mathrm{d}$ ). Six months later, he was admitted to our hospital with joint pain and swelling of hands, and inflammatory pain of the shoulder and pelvic girdles.

Blood tests showed persistent high levels of tryptase $(52 \mu \mathrm{g} / \mathrm{L})$ raising the question of patient good compliance to cetirizine treatment. Elevated C-reactive protein $(66 \mathrm{mg} / \mathrm{L})$ and accelerated erythrocyte sedimentation rate $\left(46 \mathrm{~mm}\right.$ at $1^{\text {st }}$ hour) were found. ACPA were present at a high titer (> $250 \mathrm{UI} / \mathrm{L}$ ) whereas HLA-B27 status was negative. At follow-up, X- 
rays imaging and ultrasonography showed active inflammatory and erosive polyarthritis. Rheumatoid factors, initially negative, became positive in September 2013 (RF-IgM: 46 UI/L). Clinical presentation was consistent with RA diagnosis according to ACR-EULAR 2010 criteria [1], as others causes of chronic inflammatory arthritis were eliminated. Methotrexate was contraindicated by pulmonary disorders and the presence of non hypermetabolic lung nodules. He was prescribed cortisone $7.5 \mathrm{mg} / \mathrm{day}(0.1 \mathrm{mg} / \mathrm{Kg})$, associated with painkillers (tramadol hydrochloride LP $100 \mathrm{mg}$ and acetaminophen $1 \mathrm{~g}$ ) on demand and received compliance recommendations for regular intake of cetirizine $10 \mathrm{mg} / \mathrm{d}$

Corticosteroids were progressively decreased then stopped after 3 months and mastocytosis and RA remained inactive (DAS28 at 2.3 and Tryptase levels $<20 \mu \mathrm{g} / \mathrm{L}$ ); during the three following years under antihistamine treatment alone. Last examination, perfomed in june 2016, confirmed none evolutive intracarpal, interphalangeal and metacarpophalangeal radiographic lesions without active synovitis.

\section{$\underline{\text { Discussion }}$}

\section{Mastocytosis and Mast cells}

This patient suffered from mastocytosis diagnosed 15 years ago. Mastocytosis is a disorder characterized by mast cell proliferation and accumulation within various organs. Mastocytosis is generally classified into two major types, the cutaneous mastocytosis (CM) corresponding to the accumulation of MC only in skin and the systemic mastocytosis (SM) where the accumulation is occurring in one or more organs, each could be subdivided in a total of seven different categories[2]. Little is known about mastocytosis etiology, however, abnormal mast cell activation/survival or proliferation is most commonly associated with auto-activating mutation on the tyrosine kinase receptor c-KIT[3]. 
Three types of CM are identified, urticaria pigmentosa, diffuse CM and mastocytoma of the skin, usually affecting people in childhood. The most frequently form of CM is urticaria pigmentosa characterized by yellow-brown macules located at the trunk or extremities of the body. Diffuse CM is more severe and it manifests by blisters and bullae.

SM are divided into indolent SM (ISM), SM with an associated hematopoietic non-mast cell lineage disease, aggressive SM and mast cell leukemia (MCL).

Patients affected by ISM present skin lesions, similar to urticaria pigmentosa, and bone marrow infiltration[4]. The aggressive form of mastocytosis is associated with an important infiltration of tissues and MCL is characterized by infiltration with atypic or immature Mast Cells (MCs) in organs and bone marrow.

Organ infiltration by MCs can lead to organomegaly, impairment or loss of organ function.

The different forms of mastocytosis depend on the type of MCs involved and the type and the quantity of mediators released. The evolution of CM into SM, like in our patient, is known and correlates with MCs proliferation in bones and organs[5].

MCs derive from hematopoietic stem cells. They circulate in the blood to migrate to vascularized tissues where they mature under cytokines control, particularly the stem cell factor. They contain several mediators, i.e. histamine, proteases, cytokines, chemokines, growth factors, arachidonic acid metabolites, and reactive oxygen and nitrogen species. All these mediators can be secreted by MCs after degranulation and are involved in different functions of MCs[6].

MCs can be subdivided according to their serine proteases expression (tryptase or chymase only, or both tryptase and chymase[7] or to staining characteristics of their granules and localization (connective tissue MC posseses safranin positive granules whereas mucosal mast cells are safranin-negative)[8]. 
MCs can be activated by many stimuli, via the high-affinity immunoglobulin E (IgE) receptor $(\mathrm{FccRI})$ in allergic response, after IgE cross-linking which triggers Lyn and Syk kinase cascade[9]. Pathogens such as bacteria and viruses can result on direct MCs activation through pattern recognition receptor. Other activators are cytokines, chemokines, immunoglobulin $\mathrm{G}$ via $\mathrm{Fc} \gamma$ receptor[2].

Once activated, MCs are considered as double-edged sword. In innate and acquired immunity MCs are known to act rapidly via toll-like receptors, complement receptors and Fc receptors and activate neutrophils, dendritic cells and $\mathrm{T}$ cells thanks to their mediators. MCs can also phagocyte bacteria and protect against viruses by the recruitment of $\mathrm{T}$ cells and natural killers cells [10]. Another function of MCs is their role in host defense against parasites, via IgE response[11].

Although MCs have protective effects, an abnormal activation can promote inflammatory disorders. They are mostly described for their role in anaphylaxis and allergic response by hypersensitivity reactions via $\operatorname{IgE}$ binding[12]. Accumulation of MCs mediators in airway smooth muscle are correlated with asthma activity [13]. Moreover, evidence from their overabundant representation/activity in intestine is amply described in inflammatory bowel disease (Crohn's disease or ulcerative colitis) and irritable bowel[14].

More controversially, MCs may also play a role in cancer by promoting growth of tumors via angiogenesis factors[14].

\section{Mastocytosis and osteoporosis}

Osteoporosis and vertebral fracture are frequent in patients with systemic mastocytosis with respectively $31 \%$ and $17 \%$ in a cohort of 75 adult patients[15]. Pathogenesis of mastocytosisrelated osteoporosis is not fully understood but relapse of mediators by mast cells within bone marrow is thought to be central. Histamine acts directly on osteoclasts by promoting osteoclast formation directly through paracrine action on the precursors and indirectly through 
increased osteoblasts secretion of RANKL[16]. Moreover, heparin and bone resorptive cytokines (IL-1, IL-6 TNFalpha) are known to play a role in osteoclast activation by mast cells[17].

Histomorphometric studies performed in systemic mastocytosis patients have revealed an increased number of osteoclasts due to presence of mast cells, leading to osteoporosis.[18].

Multiple bone fracture associated to high tryptase levels indicated that our patient was suffering from mastocytosis and mastocytosis induced-osteoporosis. Treatment with bisphosphonates and Vitamin D supplementation in association with antihistaminergic drugs leads to absence of bone complication during 10 years with normal BMD values. Such beneficial effects of bisphosphonates treatment in patient suffering from osteoporosis secondary to mastocytosis was already reported [15, 17, 19-22]. Our patient underwent a vertebroplasty after traumatic spinal fracture only 2 years after bisphosphonates cessation but 7 years after patient quit antihistamine treatment.

Six months later, our patient presented signs of inflammatory joint disease; blood tests and medical imaging led to the diagnosis of rheumatoid arthritis according to ACR/EULAR 2010 rheumatoid arthritis criteria[23].

\section{Mast Cells and Rheumatoid Arthritis}

Clinical implication of MCs in inflammatory arthritis is not yet well defined but has been established in several studies. Increased density of MCs in synovial tissues is found in patients with RA when compared to osteoarthritis (OA) and normal joints patients, density of mast cells correlated positively with disease severity index and swollen joint counts[24]. RAassociated mast cell hyperplasia is associated with changes in mast cells subset regarding their protease expression. In normal synovium, tryptase and chimase double positive mast cells $\left(\mathrm{MC}_{\mathrm{TC}}\right)$ are mainly found. In early inflammatory rheumatoid arthritis, specific expansion of 
tryptase only positive mast cells $\left(\mathrm{MC}_{\mathrm{T}}\right)$ is observed followed by increases of $\mathrm{MC}_{\mathrm{TC}}$ in established or chronic disease[25, 26].

Mast cells specific mediators such as histamine and tryptase are elevated in synovial fluid from RA patients[27]. Mast cells are also the main IL-17 producing cells in synovium of established RA and spondyloarthritic patient[28] contributing to synovial inflammation[29].

Several MCs activation pathways have been described in RA. In addition to toll-like receptors (TLR2, 4 and endosomal TLRs) or cytokines (IL-3, IL4 and the more recently studied IL-33[30]) mediated activation, Suurmond et al. recently demonstrated that MCs could be activated by ACPA immune complex in a citrulline-dependent manner through crosslinking Fc $\gamma$ RIIA [31]. Mast cells can also interact directly with $\mathrm{T}$ cell, contributing to $\mathrm{T}$ cell subset expansion[32] or activation[33] but also changing their own phenotype [34].

It is plausible that MCs response in RA results from integrated signals of multiple activation pathways contributing to the chronicity of disease.

Consequences of MCs activation could easily be linked to pathogenesis of RA. Indeed, once activated (by ACPA for instance), MCs produce large amount of IL-8, a potent activator of neutrophil chemotaxis[31]. MCs can also produce IL-1, TNF and IL-17, all responsible for synovial fibroblast activation and deleterious consequences on cartilage. Finally, MCs are thought to be partly responsible for drastic tissue remodeling occurring in RA. MCs are often found in the vicinity of blood synovial vessels and MC-mediators (VEGF, tryptase, chymase) are known to be potent angiogenic factors[35]. Matrix metalloproteinases (MMPs) secretion and osteoclasts activation responsible for cartilage breakdown and bone erosion, two hallmarks of RA, could be considered as consequence of MCs mediators' release. As mentioned above, MCs could activate synovial fibroblasts but also induce MMPs release by chondrocyte. Moreover, tryptase is recognized as a potent activator of MMPs[36]. 
Mechanisms explaining systemic mastocytosis-associated osteoporosis are supposed to be identical in RA, possibly though a direct effect of histamine on osteoclasts[37].

Association between MCs and inflammatory arthritis can lead to new considerations in inflammatory arthritis therapy. Recently, Bader-Meunier et al. reported the association between mastocytosis and spondyloarthritis in a series of 31 patients. They conclude that mastocytosis was associated with a higher prevalence of $\mathrm{SpA}$ and that TNF inhibitors were well tolerated in these patients[38]. On the other hand, inhibiting the c-kit receptor by imatinib, decreased MCs numbers in rheumatoid synovium extracted from patients[39], whereas sulfasalazine, a drug used to treat peripheral $\mathrm{SpA}$, was proven to have an effect on MCs[29]. In our case, antihistamine and symptomatic treatment were sufficient at a first time to manage arthritis progression while controlling MCs activity.

\section{Conclusion}

Patients with mastocytosis should be closely monitored for rheumatoid arthritis or other autoimmune diseases. One should also consider that case of mastocytosis-associated autoimmune disease are underestimated since signs and symptoms of mastocytosis are unspecific and overlap with many other diseases, correct diagnosis may be difficult and is often made later than first symptoms[4].

This case report and the literature provide data in favor of a possible development of autoimmune disease secondary to mastocytosis. Therapeutic management of these patients should take into account both mastocytosis and inflammatory arthritis.

\section{Acknowledgements}

Study design: ICV and DM. Study conduct: IL, MK. Data collection: ICV, DL. Drafting manuscript: IL, MK, JH, DM. Revising manuscript content: MK, DL, PN, JYJ, ICV, DM. 
Approving final version of manuscript: IL, MK, JH, DL, PN, JYJ, ICV, DM. ICV takes responsibility for the integrity of the data analysis. 


\section{$\underline{\text { References }}$}

1. Aletaha D, Neogi T, Silman AJ, et al (2010) 2010 rheumatoid arthritis classification criteria: an American College of Rheumatology/European League Against Rheumatism collaborative initiative. Ann Rheum Dis 69:1580-1588. doi: 10.1136/ard.2010.138461

2. Theoharides TC, Valent P, Akin C (2015) Mast Cells, Mastocytosis, and Related Disorders. N Engl J Med 373:163-172. doi: 10.1056/NEJMra1409760

3. Cruse G, Metcalfe DD, Olivera A (2014) Functional deregulation of KIT: link to mast cell proliferative diseases and other neoplasms. Immunol Allergy Clin North Am 34:219-237. doi: 10.1016/j.iac.2014.01.002

4. Magliacane D, Parente R, Triggiani M (2014) Current concepts on diagnosis and treatment of mastocytosis. Transl Med UniSa 8:65-74.

5. Golkar L, Bernhard JD (1997) Mastocytosis. The Lancet 349:1379-1385. doi: 10.1016/S0140-6736(96)07056-0

6. DeBruin EJ, Gold M, Lo BC, et al (2015) Mast cells in human health and disease. Methods Mol Biol 1220:93-119. doi: 10.1007/978-1-4939-1568-2_7

7. Moon TC, St Laurent CD, Morris KE, et al (2010) Advances in mast cell biology: new understanding of heterogeneity and function. Mucosal Immunol 3:111-128. doi: 10.1038/mi.2009.136

8. Gurish MF, Boyce JA (2006) Mast cells: ontogeny, homing, and recruitment of a unique innate effector cell. Journal of Allergy and Clinical Immunology 117:12851291. doi: 10.1016/j.jaci.2006.04.017

9. Kalesnikoff J, Galli SJ (2008) New developments in mast cell biology. Nat Immunol 9:1215-1223. doi: 10.1038/ni.f.216

10. Urb M, Sheppard DC (2012) The role of mast cells in the defence against pathogens. PLoS Pathog 8:e1002619. doi: 10.1371/journal.ppat.1002619

11. Abraham SN, St John AL (2010) Mast cell-orchestrated immunity to pathogens. Nat Rev Immunol 10:440-452. doi: 10.1038/nri2782

12. Galli SJ, Tsai M (2012) IgE and mast cells in allergic disease. Nat Med 18:693-704. doi: $10.1038 / \mathrm{nm} .2755$

13. Cruse G, Bradding P (2015) Mast cells in airway diseases and interstitial lung disease. Eur J Pharmacol. doi: 10.1016/j.ejphar.2015.04.046

14. Moon TC, St Laurent CD, Morris KE, et al (2010) Advances in mast cell biology: new understanding of heterogeneity and function. Mucosal Immunol 3:111-128. doi: 10.1038/mi.2009.136

15. Barete S, Assous N, de Gennes C, et al (2010) Systemic mastocytosis and bone 
involvement in a cohort of 75 patients. Ann Rheum Dis 69:1838-1841. doi: 10.1136/ard.2009.124511

16. Biosse-Duplan M, Baroukh B, Dy M, et al (2009) Histamine promotes osteoclastogenesis through the differential expression of histamine receptors on osteoclasts and osteoblasts. Am J Pathol 174:1426-1434. doi: 10.2353/ajpath.2009.080871

17. Rossini M, Zanotti R, Viapiana O, et al (2014) Zoledronic acid in osteoporosis secondary to mastocytosis. Am J Med 127:1127.e1-4. doi: 10.1016/j.amjmed.2014.06.015

18. Guillaume N, Desoutter J, Chandesris O, et al (2013) Bone complications of mastocytosis: a link between clinical and biological characteristics. Am J Med 126:75.e1-7. doi: 10.1016/j.amjmed.2012.07.018

19. Laroche M, Livideanu C, Paul C, Cantagrel A (2011) Interferon alpha and pamidronate in osteoporosis with fracture secondary to mastocytosis. Am J Med 124:776-778. doi: 10.1016/j.amjmed.2011.02.038

20. Marshall A, Kavanagh RT, Crisp AJ (1997) The effect of pamidronate on lumbar spine bone density and pain in osteoporosis secondary to systemic mastocytosis. Br J Rheumatol 36:393-396.

21. Brumsen C, Hamdy NAT, Papapoulos SE (2002) Osteoporosis and bone marrow mastocytosis: dissociation of skeletal responses and mast cell activity during long-term bisphosphonate therapy. J Bone Miner Res 17:567-569. doi: 10.1359/jbmr.2002.17.4.567

22. Lim AYN, Ostor AJK, Love S, Crisp AJ (2005) Systemic mastocytosis: a rare cause of osteoporosis and its response to bisphosphonate treatment. Ann Rheum Dis 64:965966. doi: 10.1136/ard.2004.029116

23. Kay J, Upchurch KS (2012) ACR/EULAR 2010 rheumatoid arthritis classification criteria. Rheumatology 51 Suppl 6:vi5-9. doi: 10.1093/rheumatology/kes279

24. Gotis-Graham I, McNeil HP (1997) Mast cell responses in rheumatoid synovium. Association of the MCTC subset with matrix turnover and clinical progression. Arthritis Rheum 40:479-489.

25. McNeil HP, Gotis-Graham I (2000) Human mast cell subsets--distinct functions in inflammation? Inflamm Res 49:3-7.

26. Olsson N, Ulfgren AK, Nilsson G (2001) Demonstration of mast cell chemotactic activity in synovial fluid from rheumatoid patients. Ann Rheum Dis 60:187-193. doi: 10.1136/ard.60.3.187

27. Buckley MG, Walters C, Wong WM, et al (1997) Mast cell activation in arthritis: detection of alpha- and beta-tryptase, histamine and eosinophil cationic protein in synovial fluid. Clin Sci 93:363-370.

28. Hueber AJ, Asquith DL, Miller AM, et al (2010) Mast cells express IL-17A in 
rheumatoid arthritis synovium. J Immunol 184:3336-3340. doi:

10.4049/jimmunol.0903566

29. Noordenbos T, Yeremenko N, Gofita I, et al (2012) Interleukin-17-positive mast cells contribute to synovial inflammation in spondylarthritis. Arthritis Rheum 64:99-109. doi: 10.1002/art.33396

30. Moulin D, Donzé O, Talabot-Ayer D, et al (2007) Interleukin (IL)-33 induces the release of pro-inflammatory mediators by mast cells. Cytokine 40:216-225. doi: 10.1016/j.cyto.2007.09.013

31. Suurmond J, Rivellese F, Dorjée AL, et al (2014) Toll-like receptor triggering augments activation of human mast cells by anti-citrullinated protein antibodies. Ann Rheum Dis annrheumdis-2014-205562. doi: 10.1136/annrheumdis-2014-205562

32. Suurmond J, van Heemst J, van Heiningen J, et al (2013) Communication between human mast cells and CD4(+) T cells through antigen-dependent interactions. Eur J Immunol 43:1758-1768. doi: 10.1002/eji.201243058

33. Nakae S, Suto H, Kakurai M, et al (2005) Mast cells enhance T cell activation: Importance of mast cell-derived TNF. Proc Natl Acad Sci USA 102:6467-6472. doi: 10.1073/pnas.0501912102

34. Baram D, Vaday GG, Salamon P, et al (2001) Human mast cells release metalloproteinase- 9 on contact with activated T cells: juxtacrine regulation by TNFalpha. The journal of Immunology 167:4008-4016.

35. Suurmond J, van der Velden D, Kuiper J, et al (2015) Mast cells in rheumatic disease. Eur J Pharmacol. doi: 10.1016/j.ejphar.2015.03.085

36. Magarinos NJ, Bryant KJ, Fosang AJ, et al (2013) Mast cell-restricted, tetramerforming tryptases induce aggrecanolysis in articular cartilage by activating matrix metalloproteinase-3 and -13 zymogens. J Immunol 191:1404-1412. doi: 10.4049/jimmunol.1300856

37. Seitz S, Barvencik F, Koehne T, et al (2013) Increased osteoblast and osteoclast indices in individuals with systemic mastocytosis. Osteoporos Int 24:2325-2334. doi: 10.1007/s00198-013-2305-x

38. Bader-Meunier B, Livideanu CB, Larroche C, et al (2014) Association of mastocytosis with inflammatory joint diseases_A series of 31 patients. Seminars in Arthritis and Rheumatism 44:362-365. doi: 10.1016/j.semarthrit.2014.05.016

39. Eklund KK (2007) Mast cells in the pathogenesis of rheumatic diseases and as potential targets for anti-rheumatic therapy. Immunol Rev 217:38-52. doi: 10.1111/j.1600065X.2007.00504.X 